\title{
Indexation of Acta Cirúrgica Brasileira in the Institute for Scientific Information. What now?
}

\author{
Orlando de Castro e Silva Jr* \\ * Full Professor and Head of the Division of Digestive Surgery, Department of Surgery and Anatomy, Faculty of Medicine of Ribeirão Preto, \\ University of São Paulo, Brazil. \\ Consulting editor, Scientific Committee of Acta Cirúrgica Brasileira.
}

After the initial euphoria about the recent inclusion of Acta Cirúrgica Brasileira in the Thomson Reuters (Former Institute for Scientific Information-ISI) it is necessary to reflect about the future of the Acta regarding the citation of the papers published in it, especially by Brazilian investigators. A further increase of the impact factor of the journal will come from the citation of its papers, and this should be the future goal of the editor and the editorial board. Thus, it is necessary to change the attitude of Brazilian scientists about the need to cite the work of their fellow countrymen, both for the good of Brazilian science in general and of Acta Cirúrgica Brasileira in particular. It will be up to the authors to judge the necessity and the opportunity for the citations.

It has long been known that Brazilian scientists do not feel at ease in citing papers of their Brazilian colleagues or peers published either in international or, and especially, in Brazilian journals. The old story that "Brazilians don't cite Brazilians" continues to be true in the literature ${ }^{1,2}$. I definitely feel that this omission is not simply due to lack of information. When somebody publishes a paper in his area of expertise it is his duty to be aware of what is being studied in his country, obviously, as long as the topic in question has been published. Thus, the topic is expected to be referred to, discussed and compared, showing transparency in the concepts presented. This shows detachment on the part of the author, who submits his truth to discussion in a comparison with similar Brazilian or international studies.

Although they are indexed in Medline, original Brazilian contributions disappear from the Brazilian literature. This is the case for various papers that I had the opportunity to analyze in various Brazilian journals as well as in Acta, in which no reference was made to important contributions by Brazilian authors. For example, several times I read statements of this type by authors: "Such and such sign.....of such and such disease... has not been previously described in Brazil...", where previous reports did exist, but were "hidden in the Brazilian literature". I recently saw a published article in which the authors stated: "We did not identify in the national literature surgical recommendations for patients with...". However, a paper on this topic had been previously published in the same journal. Thus, several Brazilian articles are simply not cited. And in the Acta itself, not infrequently authors do not cite other au- thors who deal with the same topic. Before the availability of search sites, it was difficult or even impossible to note these omissions, which were not detected or, in most case, were only detected by the overlooked author. We may state that there is a "congenital malformation" among Brazilian authors. Postgraduation programs would have the opportunity to correct this defect in order to train properly their investigators. Indeed, proper attention is not devoted "to the seriousness of bibliographic research and to respect for previous authors."

With the democratization of knowledge, especially over the last ten years, it has become easy for the reader to judge the quality of a scientific paper by analyzing in an extremely rapid manner the quality of cited papers, the pertinence of the citation, the originality of the investigation and the importance of its insertion in the world scientific scene, and also to note the papers that were not $\operatorname{cited}^{3,4}$. As a consequence, we become more critical and more demanding regarding the citation topic. Thus, an appropriate citation should be made in a judicious manner according to justice, merit and ethical criteria. Failing to cite a paper in order to show originality, overlooking authors or groups in the same area of activity is something of the past and should no longer be tolerated today in an era with the internet as a search medium. Today, ignoring a paper actually belittles the author and his published investigation more than the author that was not cited.

Citing papers is a necessary exercise that gives an author the opportunity to exhibit his knowledge of the subject and his intellectual agility by comparing his knowledge to that of others in related areas. Also, by citing the papers published in a journal he contributes to the divulgation of the journal in question, with a consequent increase in the impact factor of the latter. In addition, and just as important, he gives visibility to the Brazilian scientific culture through the journal chosen.

Brazilian science has been compared in the past to an iceberg, with $80 \%$ of Brazilian production remaining submerged. Most of the publications of this $80 \%$ portion of Brazilian scientific production have not emerged because of lack of quality. So much so that the international scientific community became interested in the problem of this iceberg base after the publication of an article by $\mathrm{Gibbs}^{5}$ who called it "lost science of the third world. 
Recent data indicate that the impact factor of the few Brazilian journals indexed in ISI has increased significantly since their inclusion in SciELO. This indicates that the electronic information networks generate international repercussions of the publications and have stimulated the investigators to submit their papers to electronic journals with the high standards of Acta Cirúrgica Brasileira. This journal represents today the legacy of academic surgeons (blue community), built with great effort. What we can do now is to contribute to increasing its impact factor to the level the journal deserves, especially after reaching the status of a journal indexed in Thomson Reuters ${ }^{2}$.

After its indexation in Thomson Reuters, the growth of the importance and impact of Acta Cirúrgica Brasileira will fundamentally depend on all those who publish their papers in the journal, whether or not they are members of SOBRADPEC, by citing or referring to the largest possible number of articles published in the journal in new scientific contributions to be submitted for publication in Acta or in any other journal indexed by SciELO or in international journals. Through the hypertext links, the citations can be accessed in any data bank and be counted for the calculation of the impact factor. It should be remembered that Acta was founded more than 20 years ago and has published many papers of good quality that need and deserve to be cited in our indexed periodicals ${ }^{2}$.
Finally, we should understand that the indexation of Acta in Thomson Reuters is a fantastic conquest, but we, and especially SOBRADPEC members, should also be aware of the fact that it is now necessary to increase its impact factor. For this it is necessary to increase the number of citations, just and adequate, of Acta papers in Acta and in other journals. On this basis, nothing more opportune now than to congratulate Professor Goldenberg for the idea, organization and maintenance of Acta Cirúrgica Brasileira.

\section{References}

1 - Goldenberg S. Gastric varices: a retrospective appraisal in hepatosplenic schistosomiasis mansoni. Acta Cir Bras. 2003;18(3):172-7. Disponível em URL: http://www.scielo.br/acb

2 - Medeiros AC. O fator de impacto da Acta Cirúrgica Brasileira. Acta Cir Bras. 2003;18(2):74-5. Disponível em URL: http:// www.scielo.br/acb

3 - Pellizzon RF, Población DA, Goldenberg S. Pesquisa na área da saúde: seleção das principais fontes para acesso à literatura científica. Acta Cir Bras. 2003;18(6):493-6. Disponível em URL: http:// www.scielo.br/acb

4 - Monteiro R, Jatene FB, Bernardo WM, Oliveira SA. Ways of searching for scientific information. Rev Bras Cir Cardiovasc. 2003;18(2): 9-12. 5 - Gibbs WW. Lost science in the third world. Sci Am. 1995;273:76-83.

\section{Correspondence:}

Orlando de Castro e Silva Jr.

R. Campos Sales, 890/9 andar

14015-110 Ribeirão Preto - SP Brazil

orlandocsj@hotmail.com 